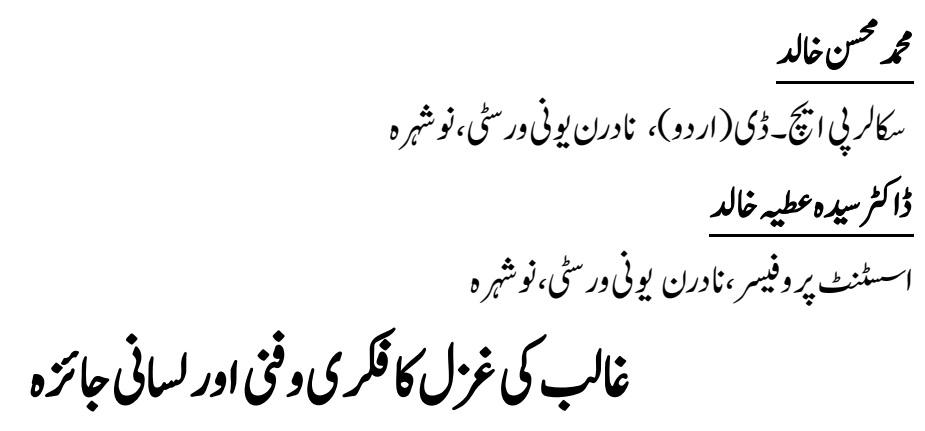

Muhammad Mohsin Khalid

Ph.D. Scholar (Urdu), Northern University, Nowshera.

Dr. Syeda Attia Khalid

Assistant Professor, Northern University, Nowshera.

\title{
Intellectual and Artistic and Linguistic Review of Ghalib's Ghazal
}

Mirza Ghalib enjoys a unique place in Urdu literature. The message of universalism in his poetry combined with his philosophical approach grant him the stature which is yet to be achieved by any other Urdu poet. In the following pages an effort is being made to have an overview of his poetry examining it at different yardsticks. The purpose is to highlight the salient characteristics of his personality as well as of his poetry. One can hardly doubt the depth of thoughts and technical mastery in his poetry which set very high standards not only in Urdu poetry but the poetry of the world at large. The dominant characteristic of his poetry is his logical way of narration. His poetry contains unparalleled pieces of imaginary. The use of words depict a great command on language. The language is used as an art in his couplets and it deeply reflects the societal values of not only his time but also the gradual evaluation of civilisations. One can easily find a musical rhythm used in his poetry like an artist. It is hard to decide whether Ghalib became great for writing his Ghazals or Urdu ghazal was honoured to have a poet like Him. There is no doubt that he is the brightest moon in the galaxy of classical Urdu Ghazal.

Keywords: Mirza Ghalib, Vrdu Literature, Poetry, Philosophical, Imaginary.

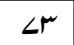




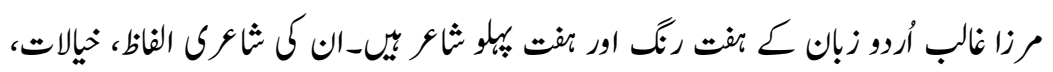

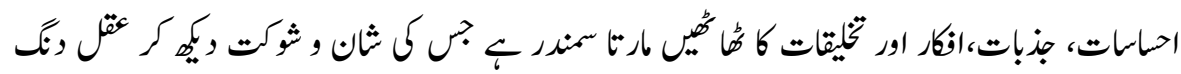

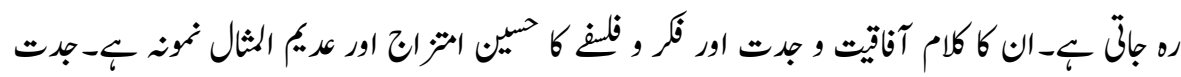

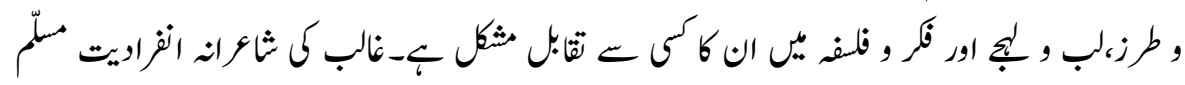

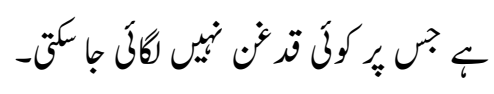

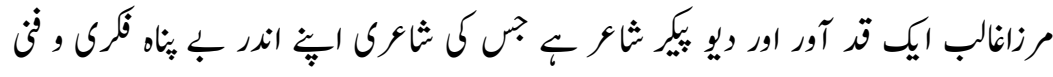

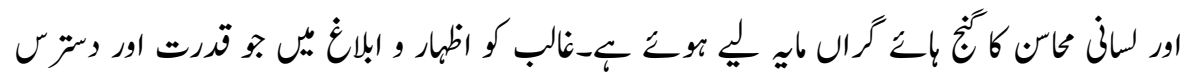

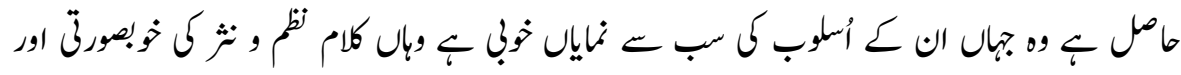
,

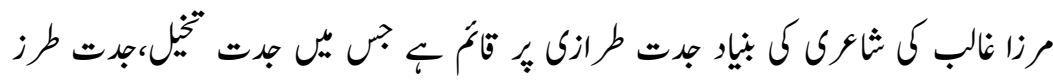

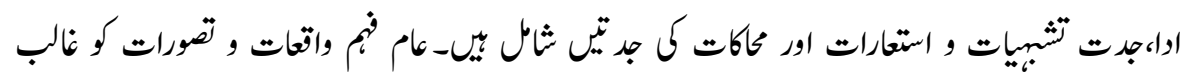

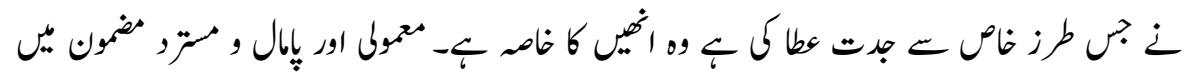

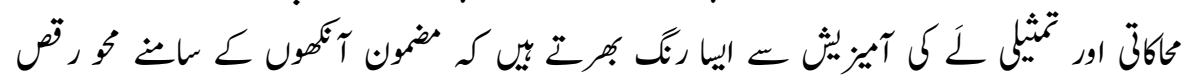

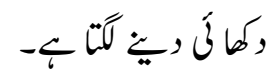

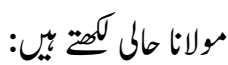

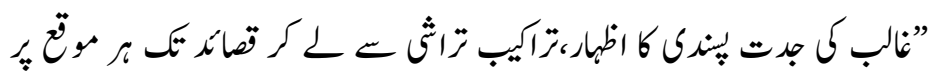

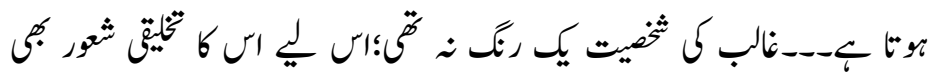

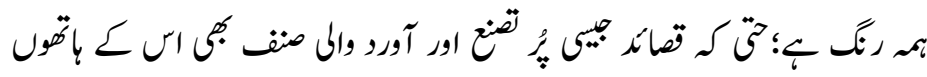

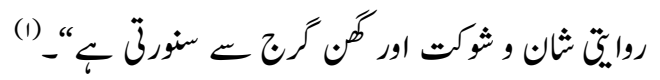

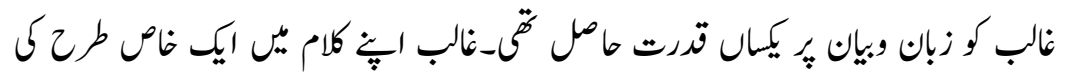

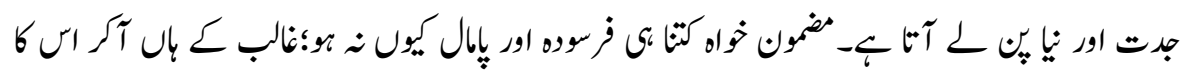

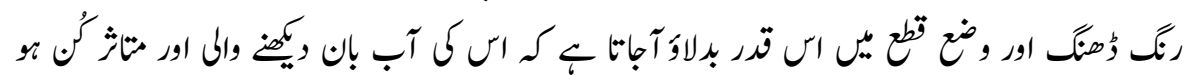
بانق ب- 


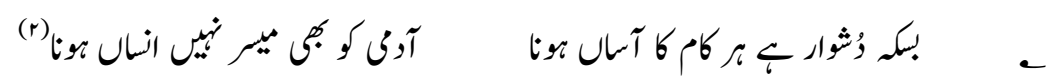

(r) e

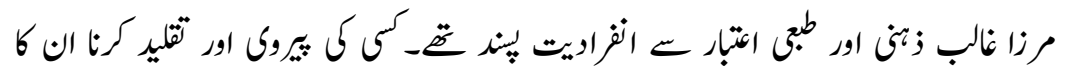

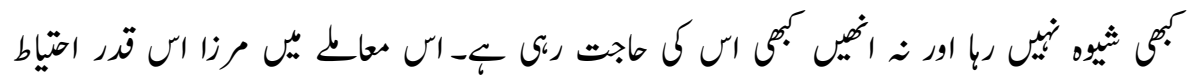

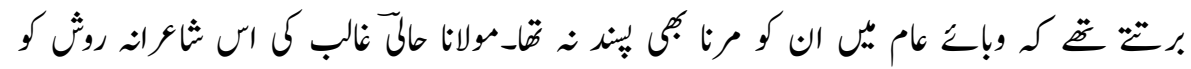

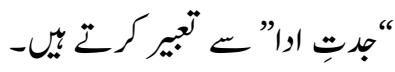

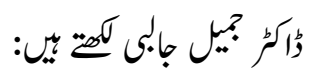

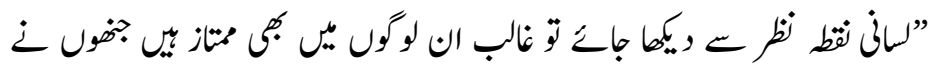

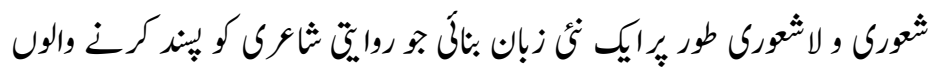

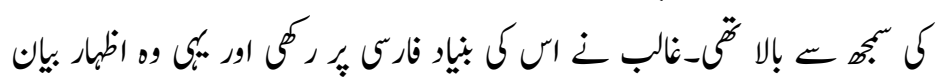

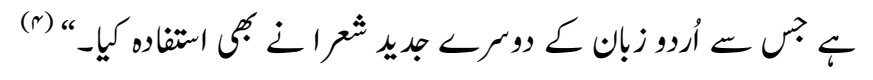

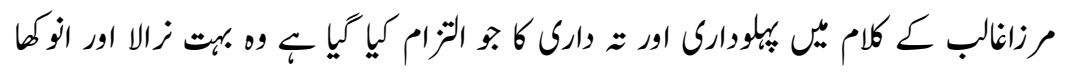

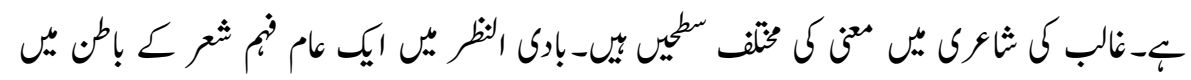

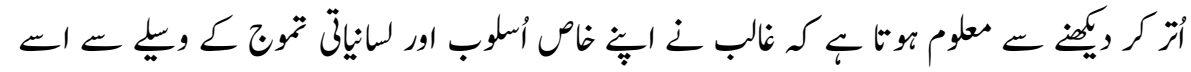
غير متمول بنا ويا بع-

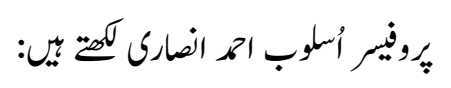

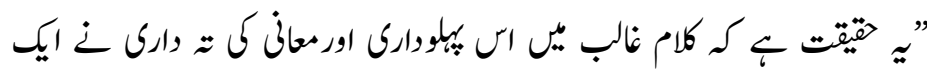

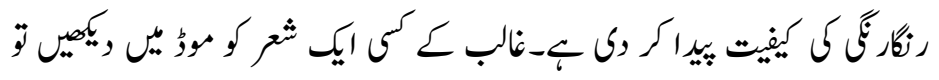

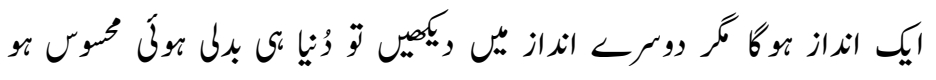

$$
\text { (a) “ }-\zeta
$$

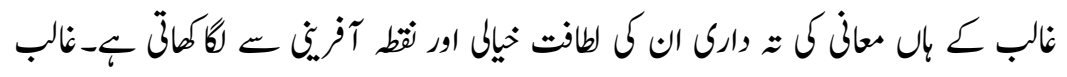

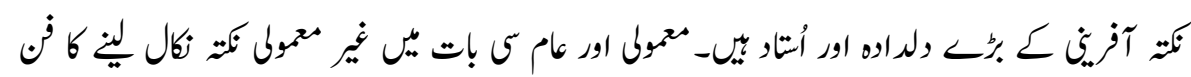

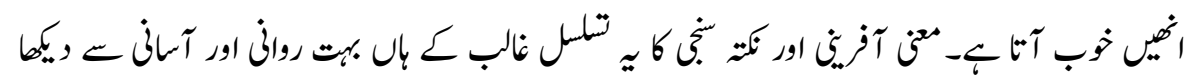




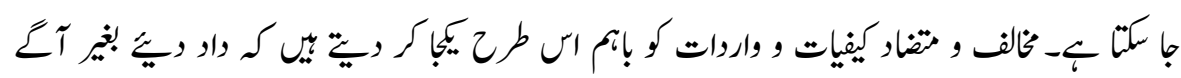

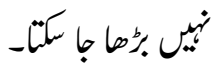

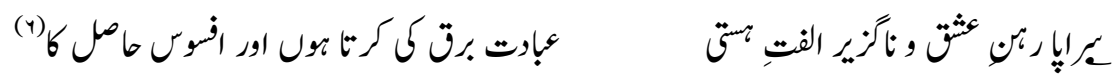

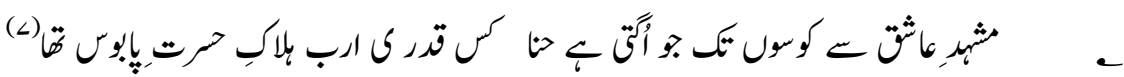

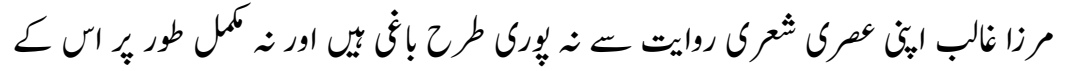

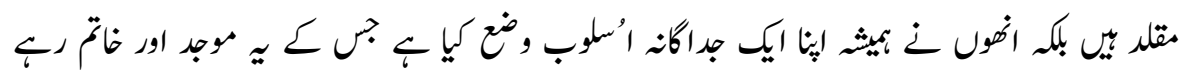
$-U^{-6}$

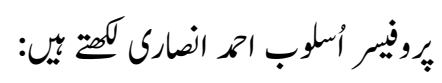

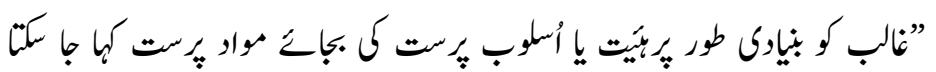

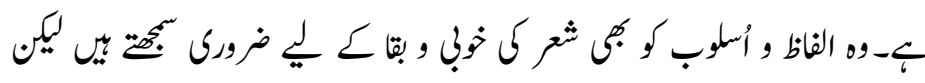

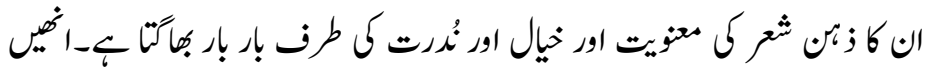

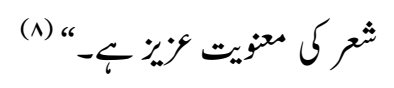

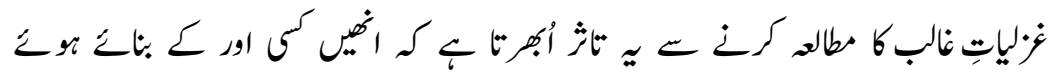

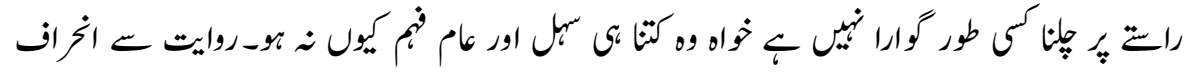

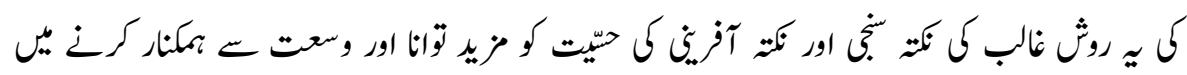

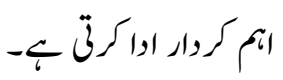

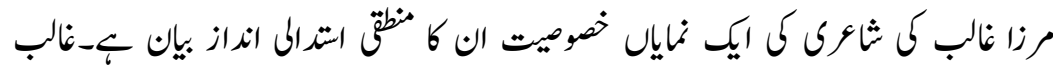

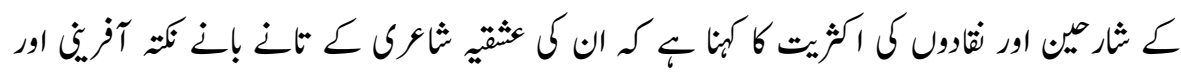

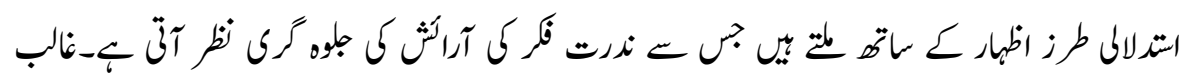

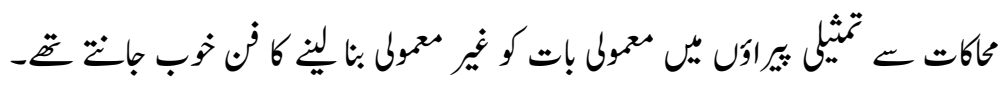

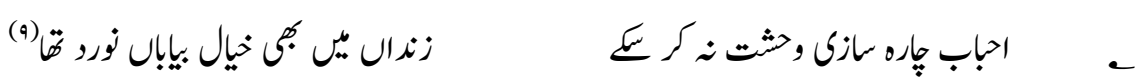

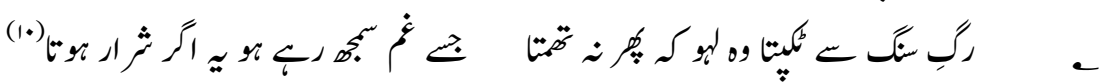




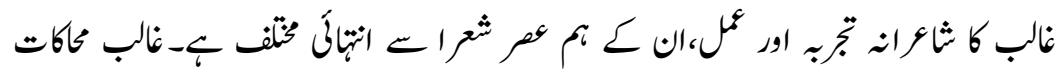

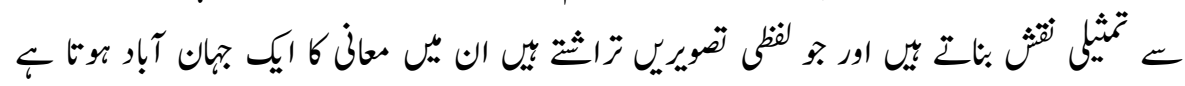

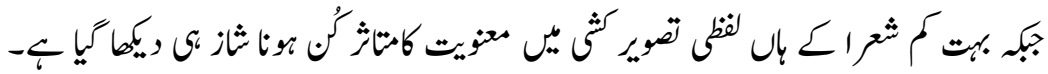

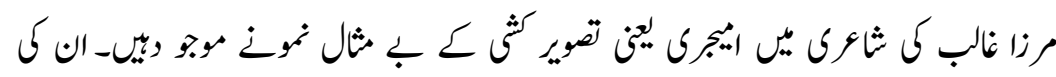

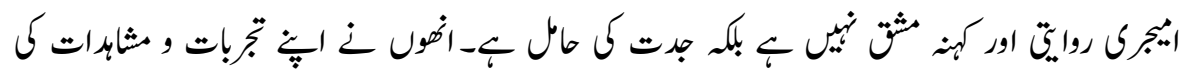

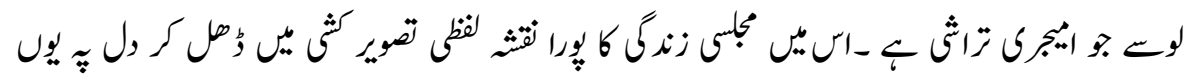

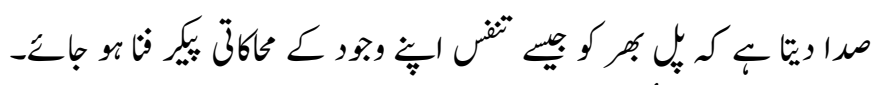

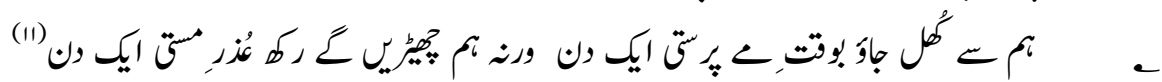

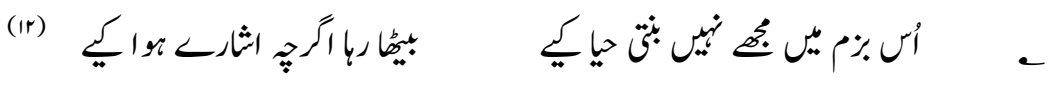

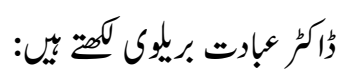

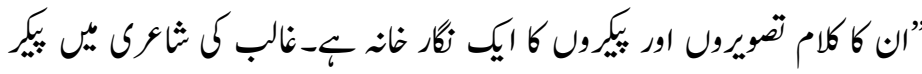

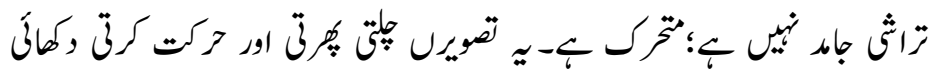

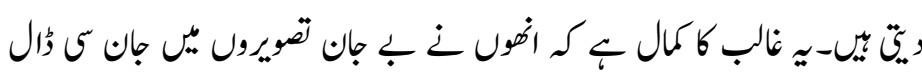

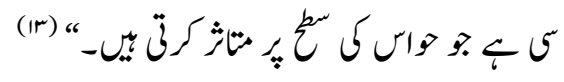

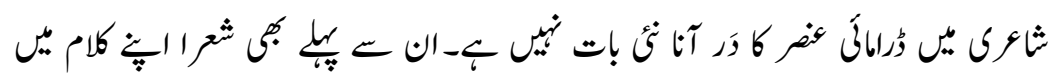

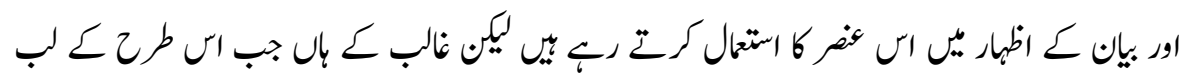

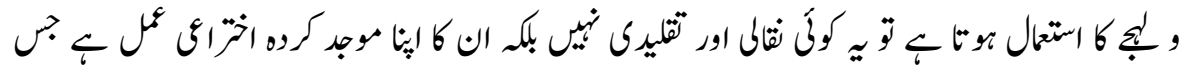

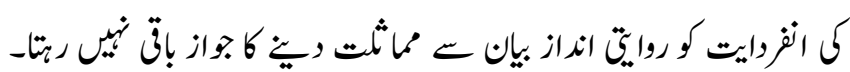

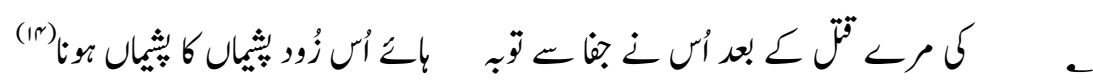

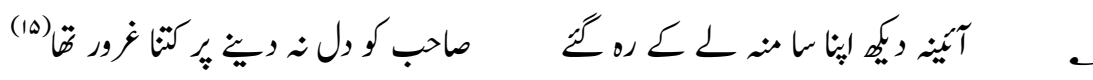

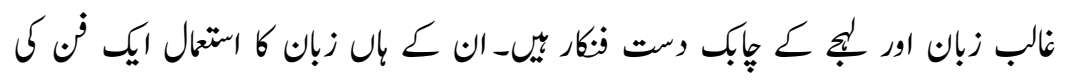

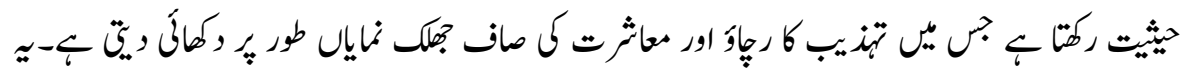

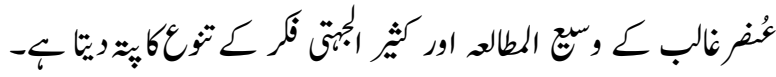




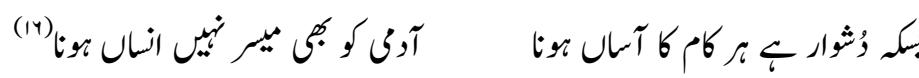

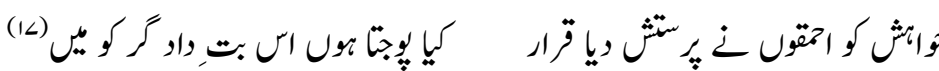

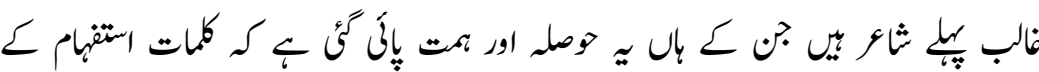

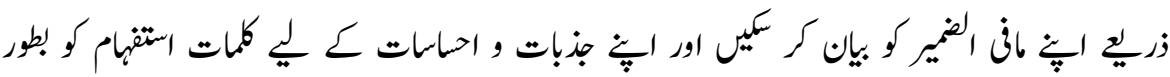

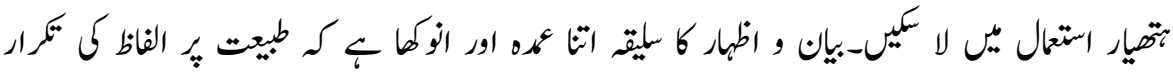

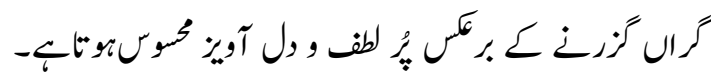

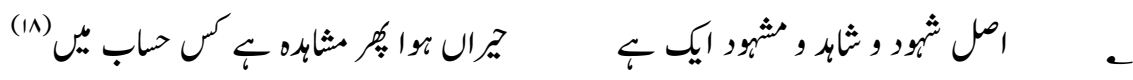

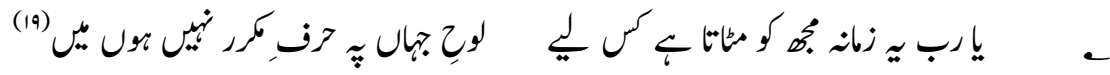

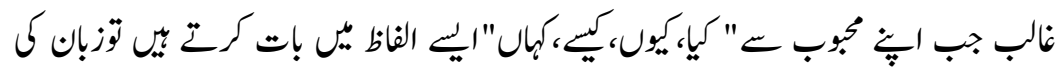

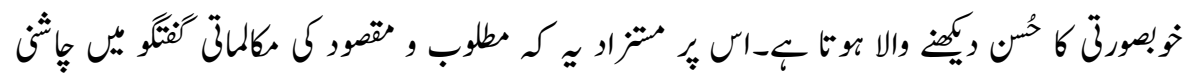

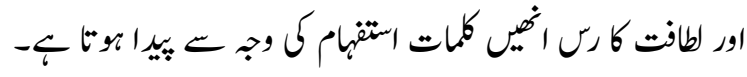

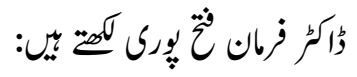

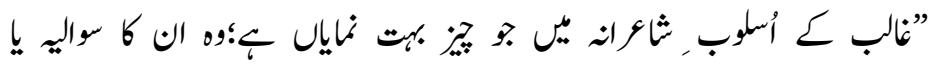

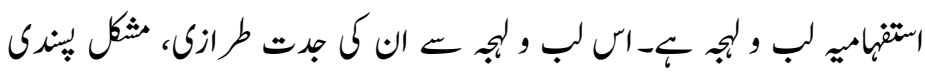

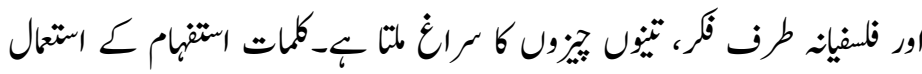

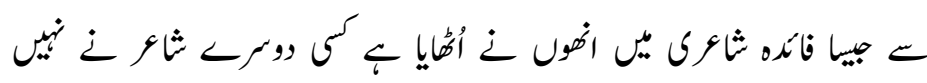

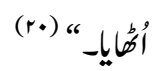

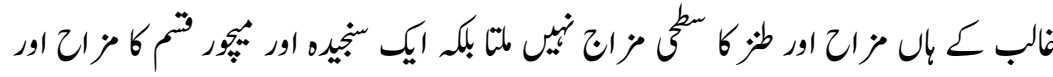

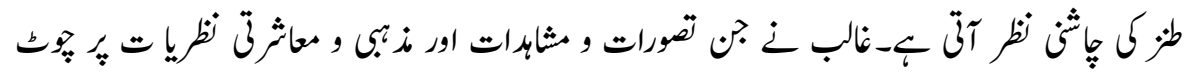

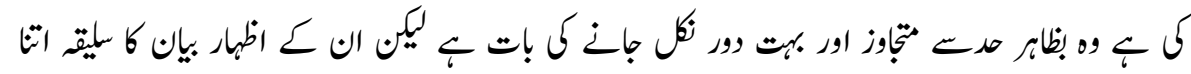

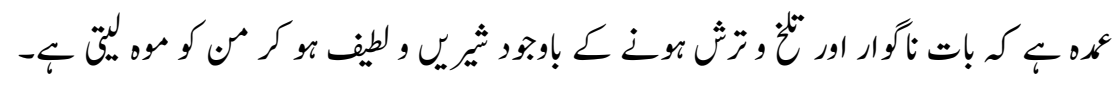

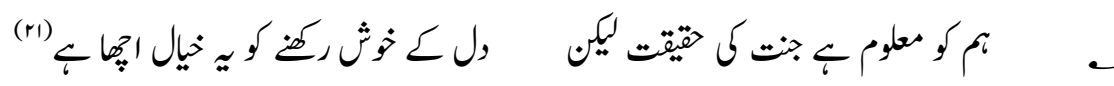

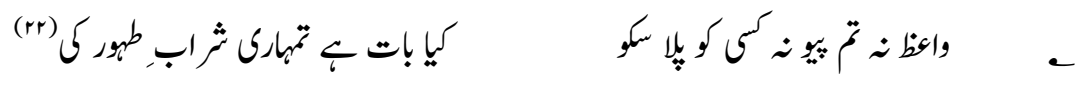




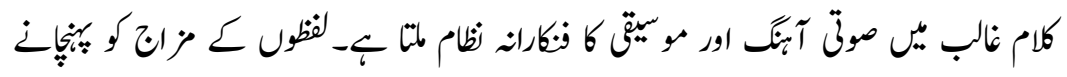

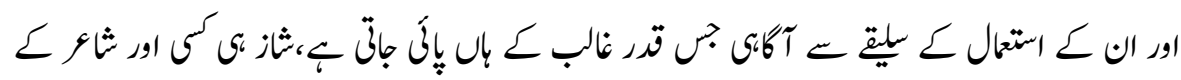

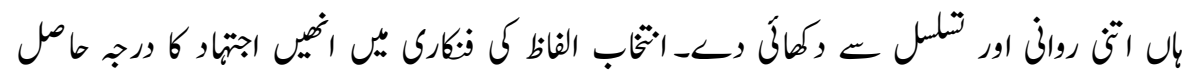

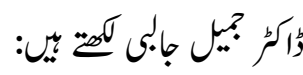

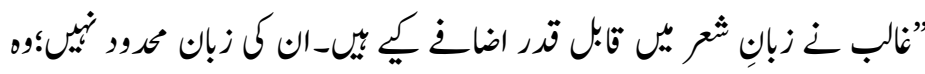

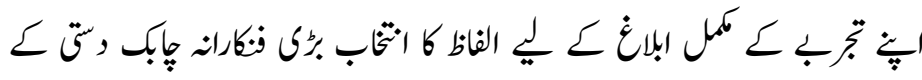

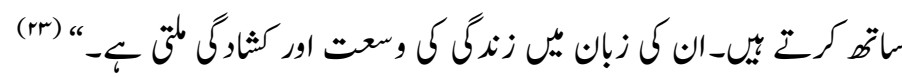

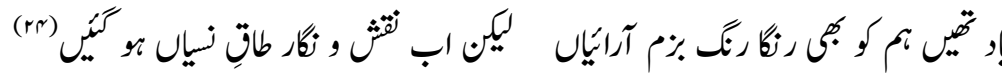

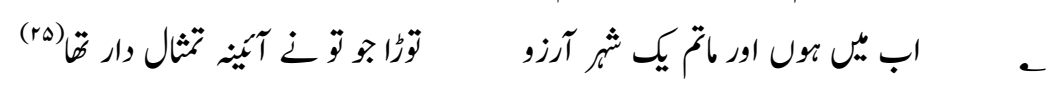

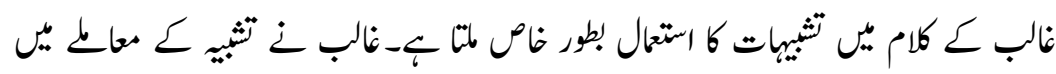

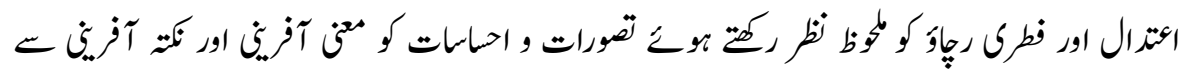

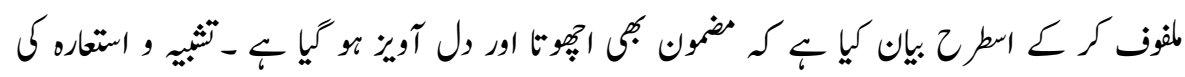

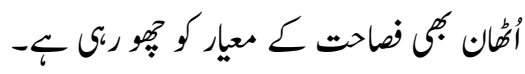

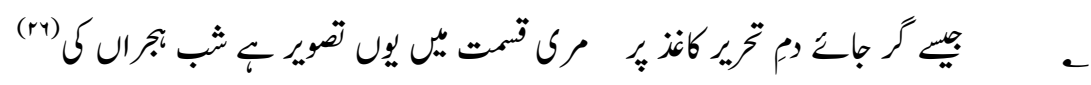

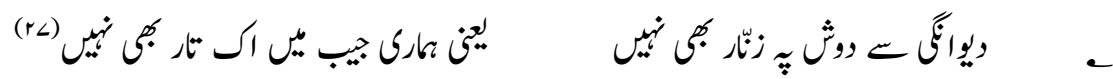

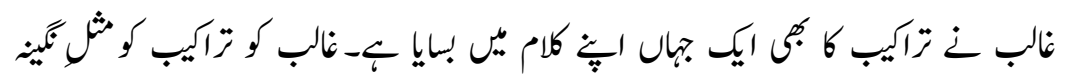

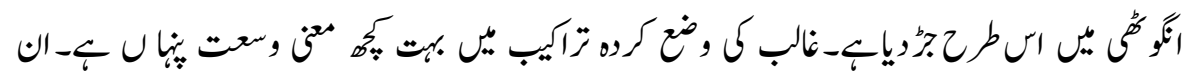

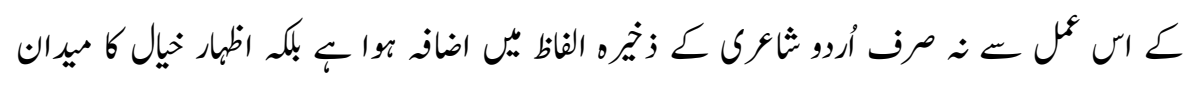

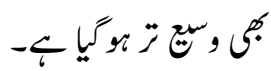
e 


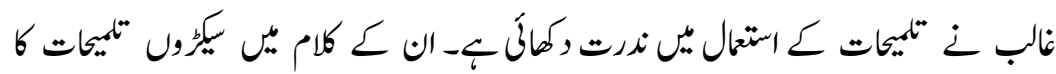

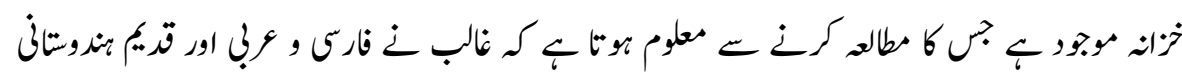

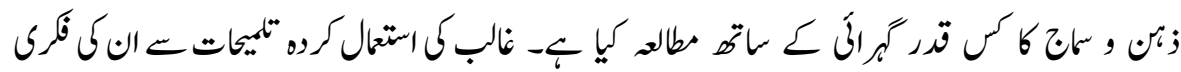

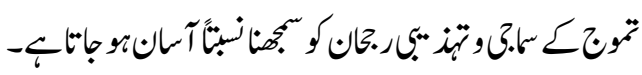

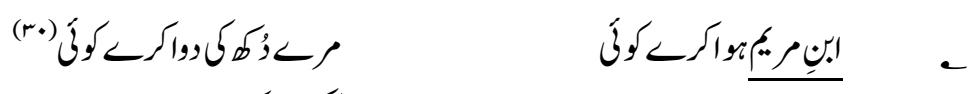

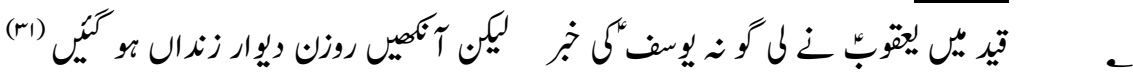

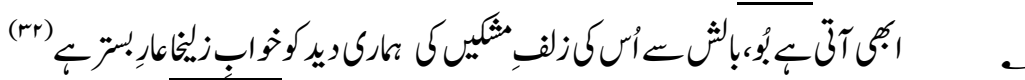

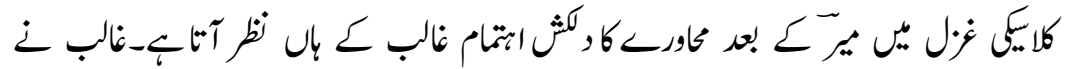

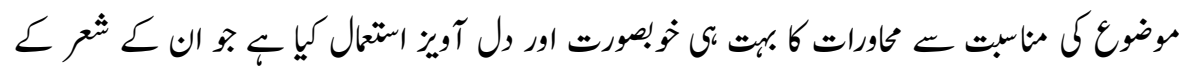

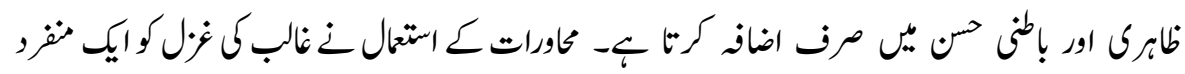

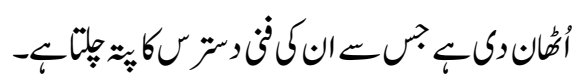

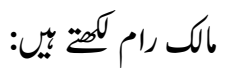

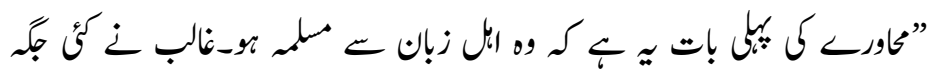

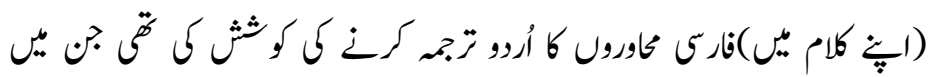

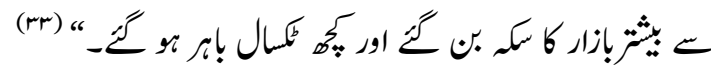

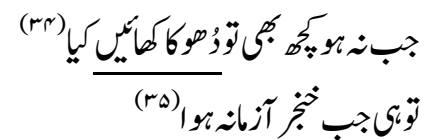

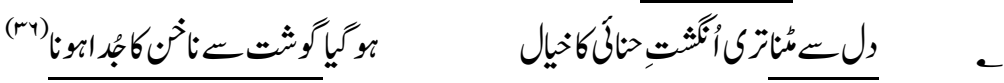

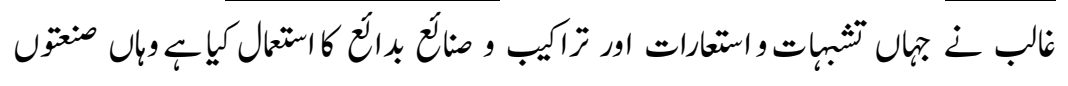

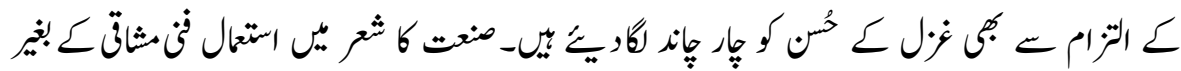

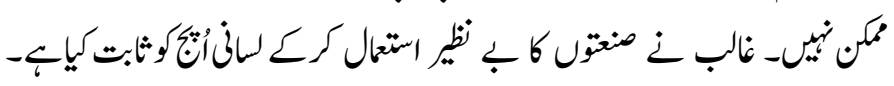

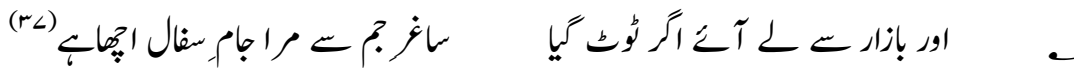

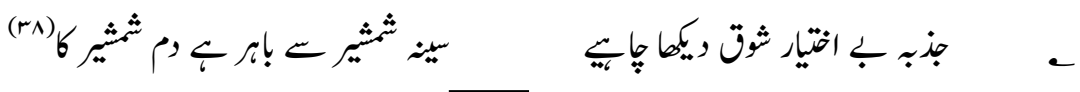




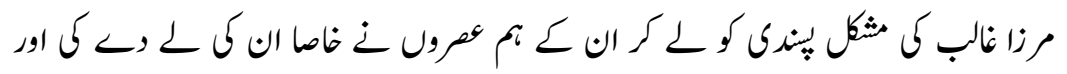

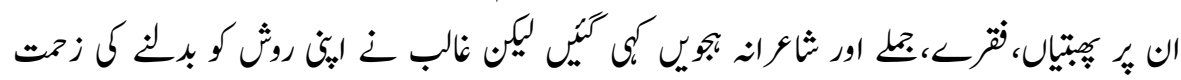

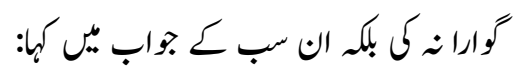

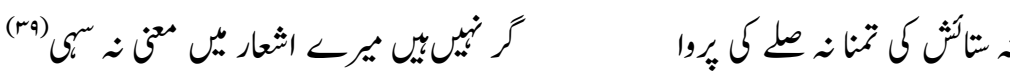

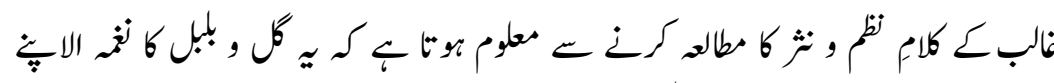

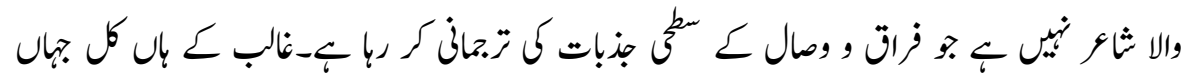

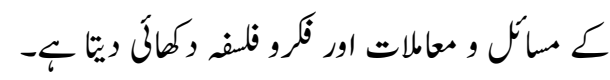

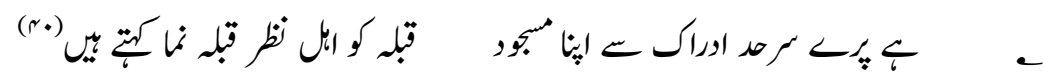

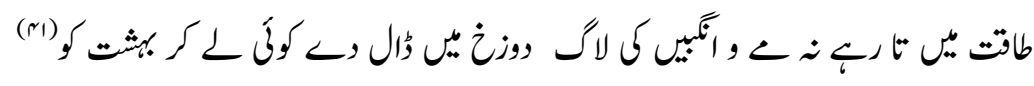

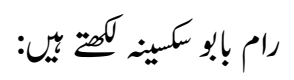

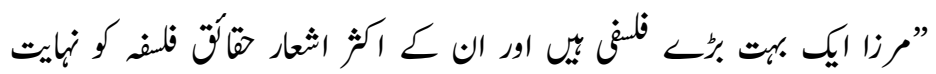

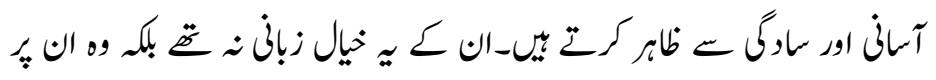

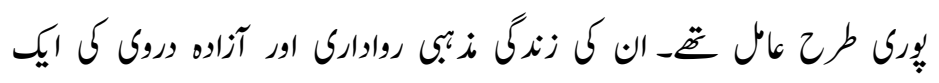

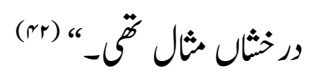

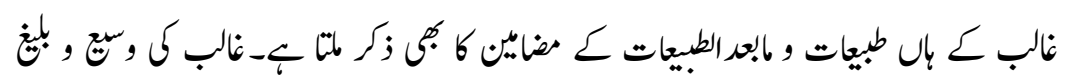

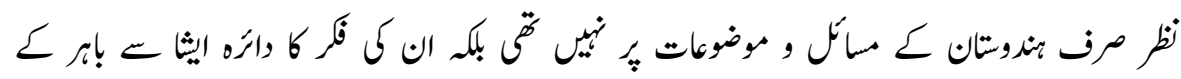

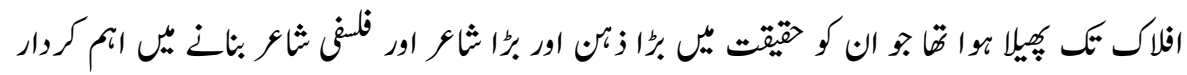
اواكر ربإنا

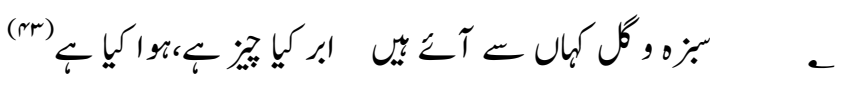

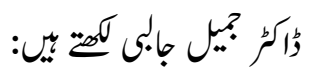

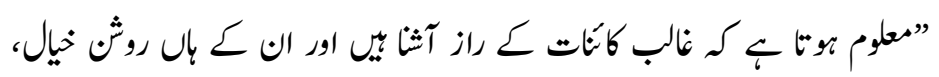

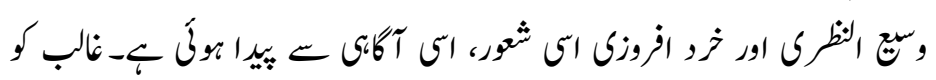




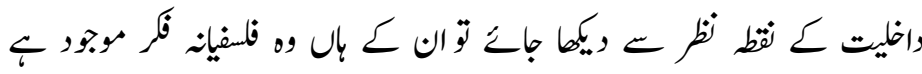

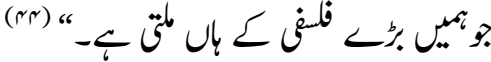

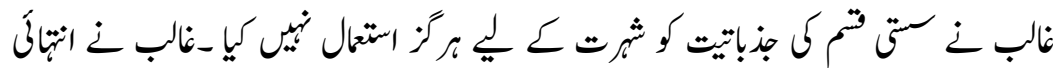

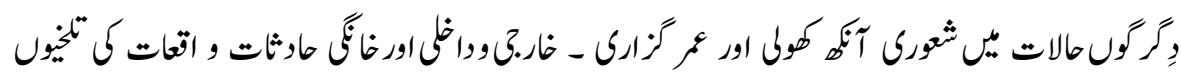

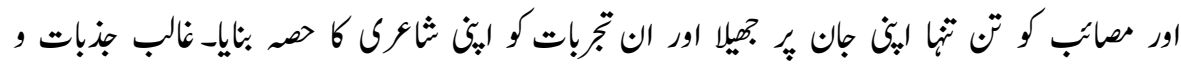

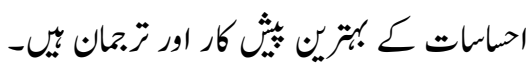

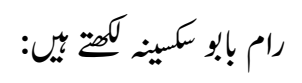

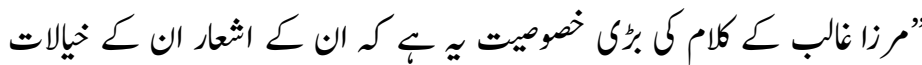

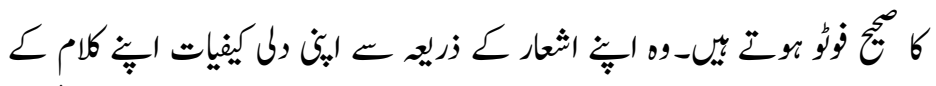

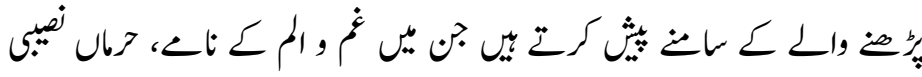

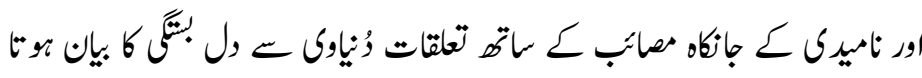

$(\sim \Delta)$ “

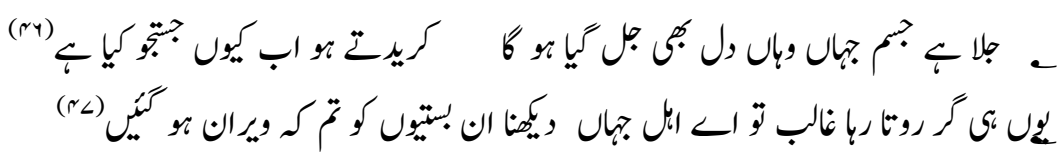

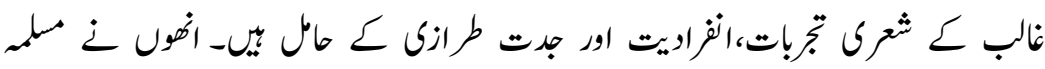

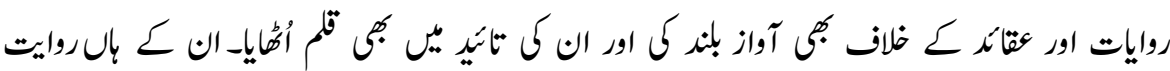

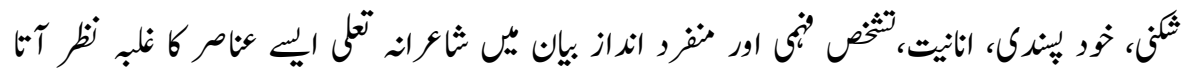

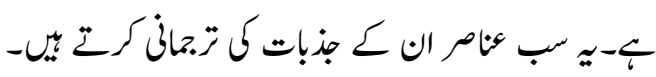

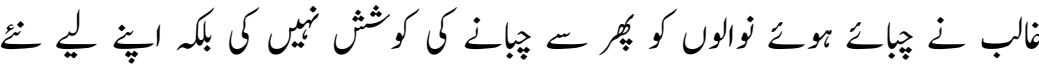

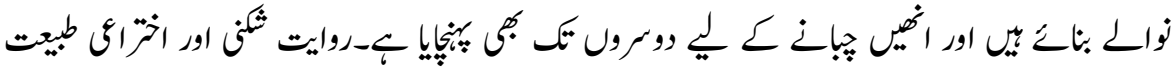

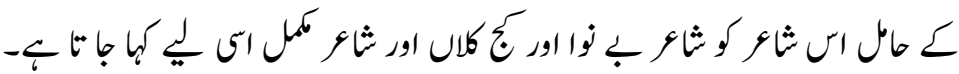

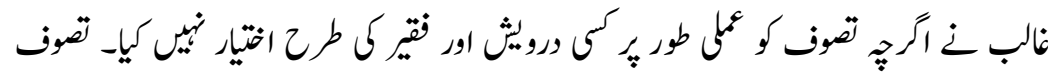

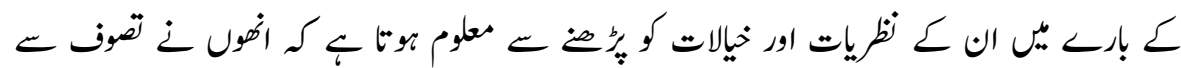




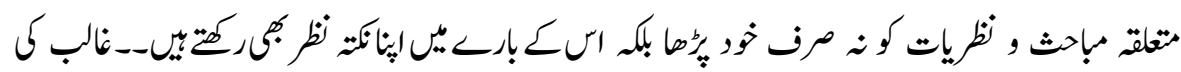

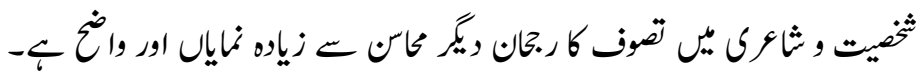

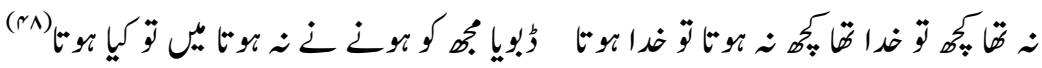

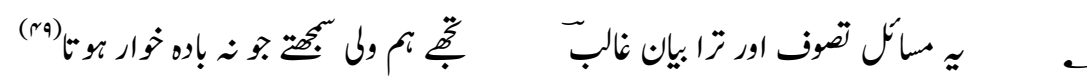

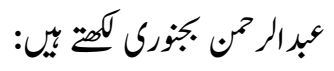

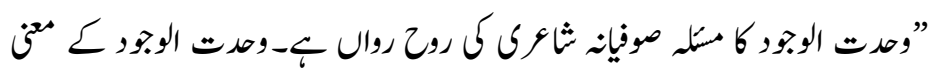

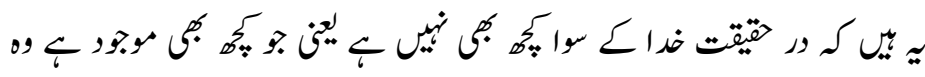

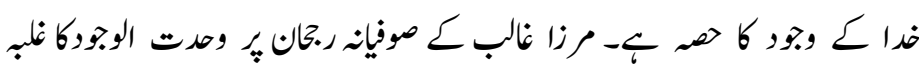

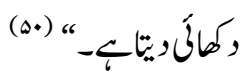

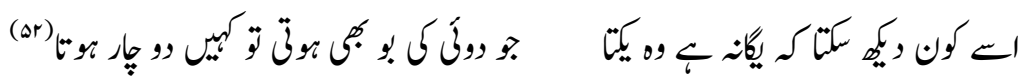

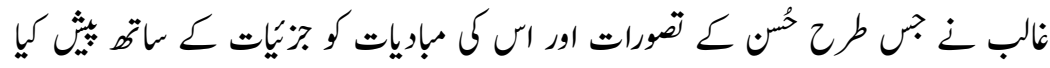

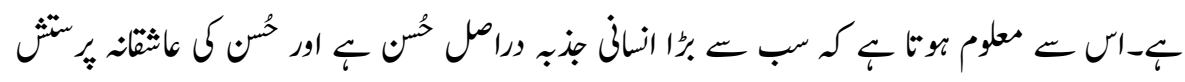

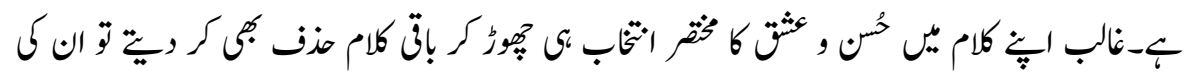

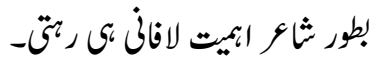

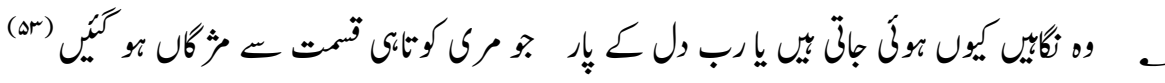

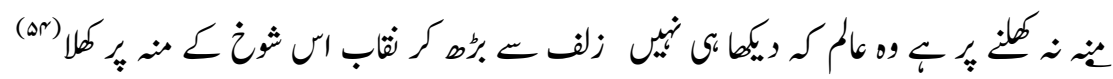

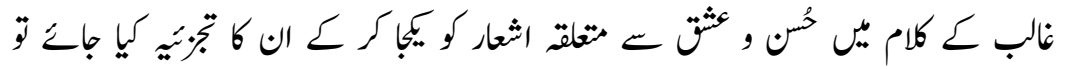

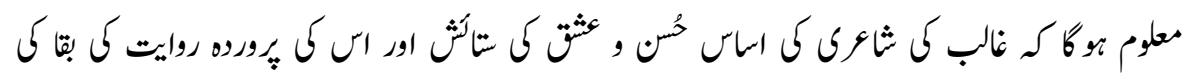

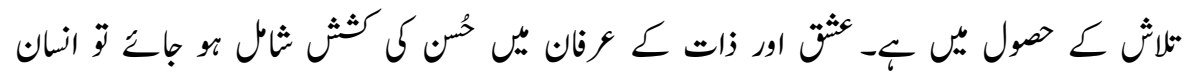

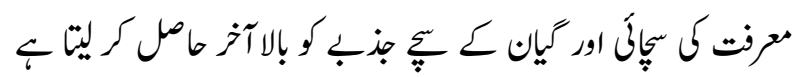

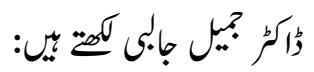




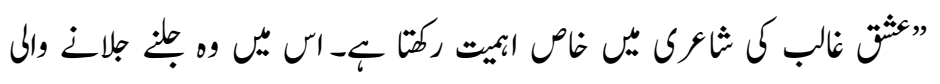

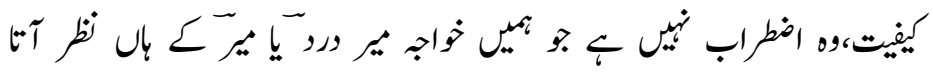

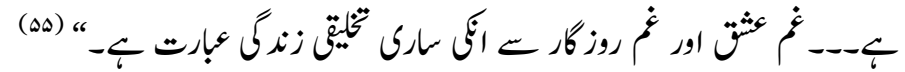

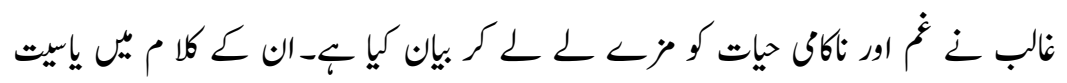

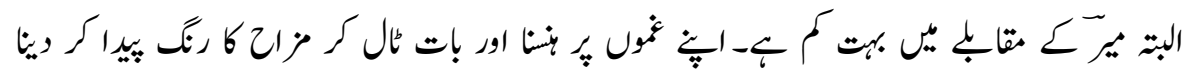

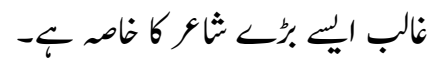

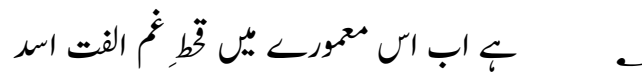

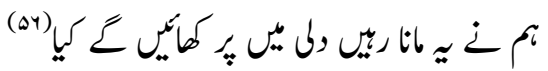
e

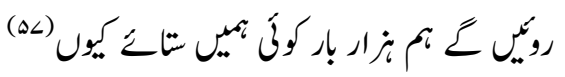

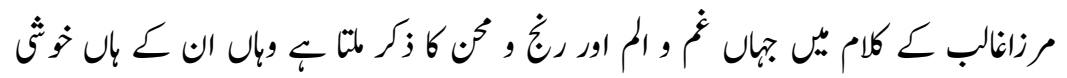

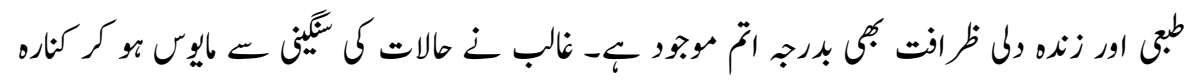

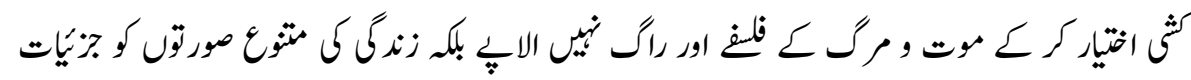

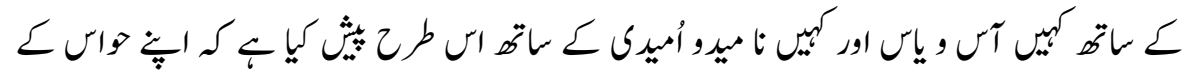

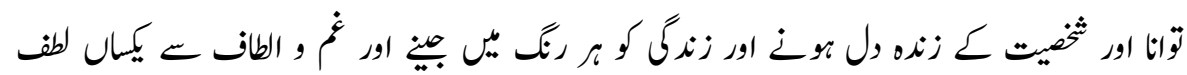

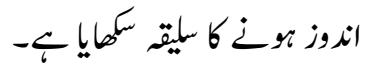

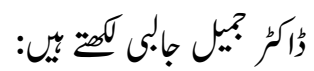

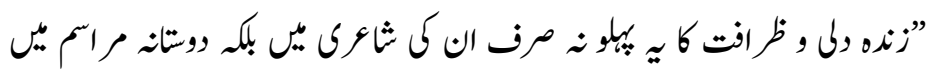

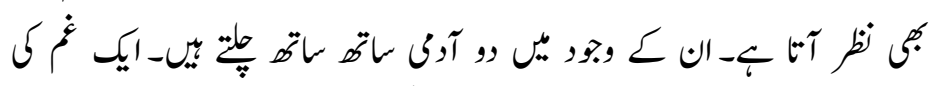

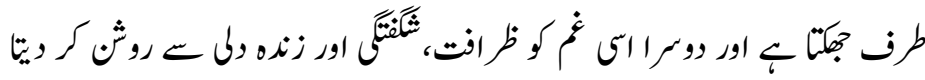

(จง) “

(هa)

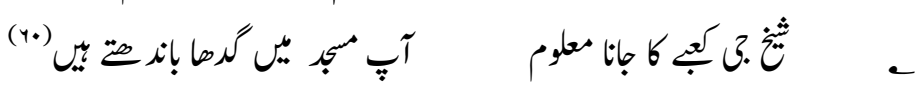




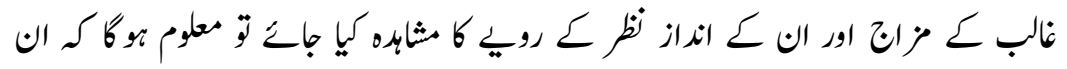

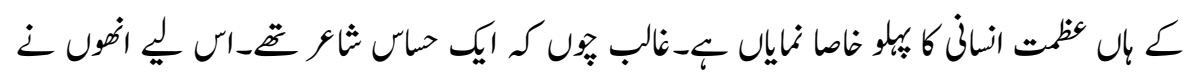

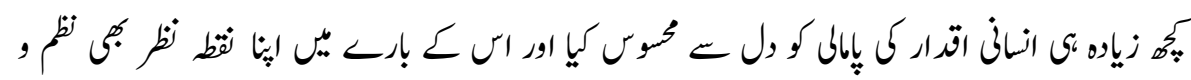

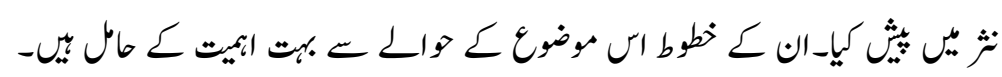

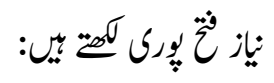

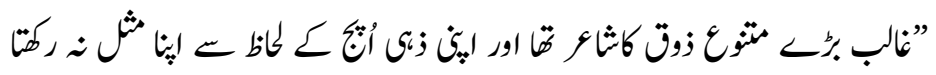

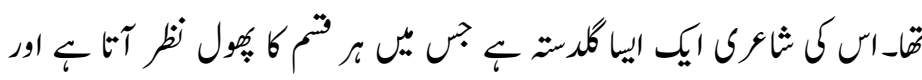

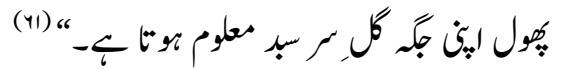

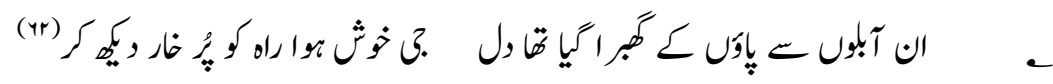

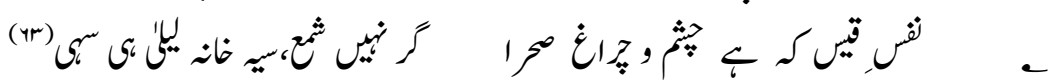

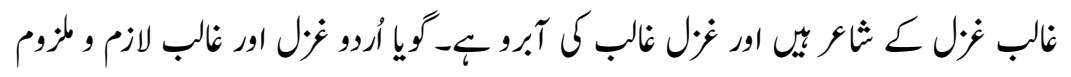

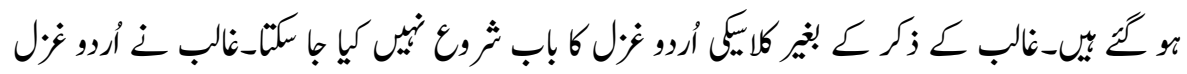

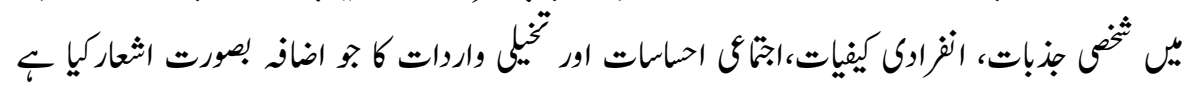

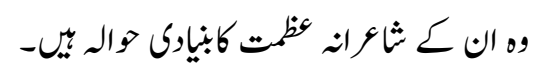

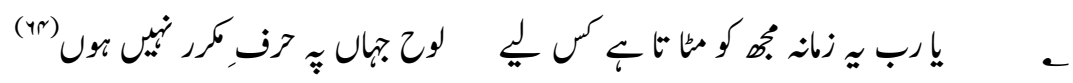

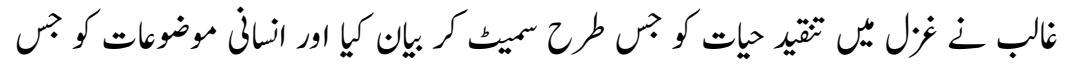

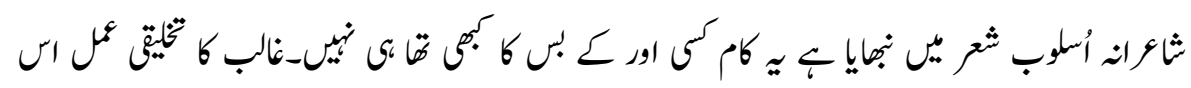

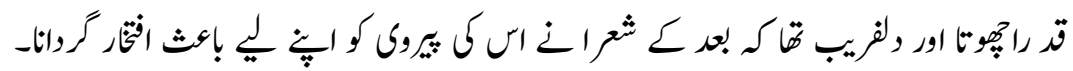

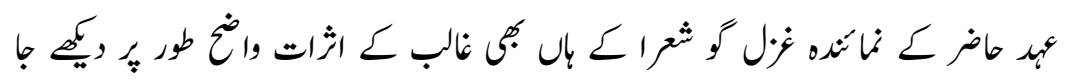

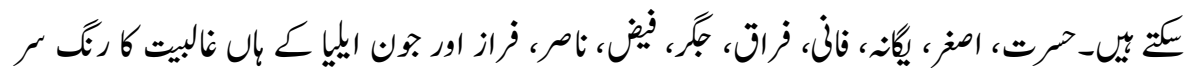

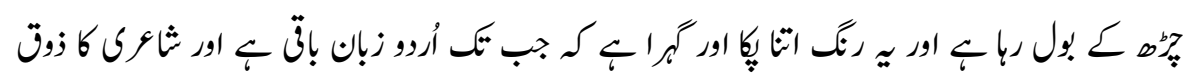

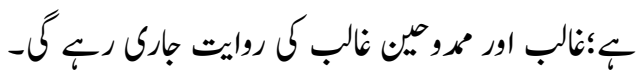

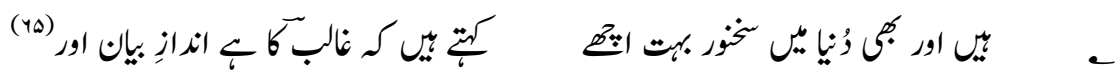




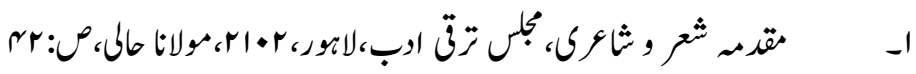

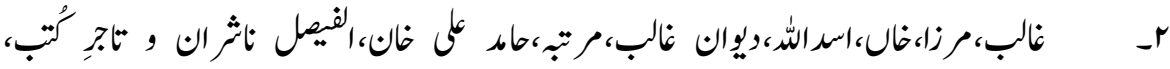

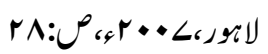

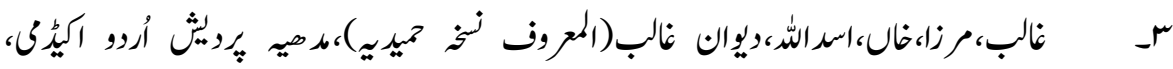

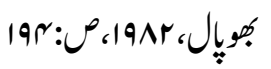

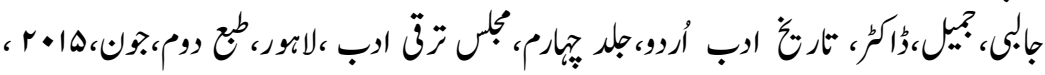

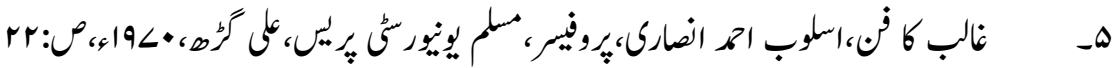

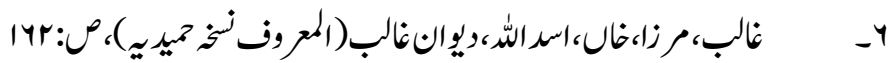

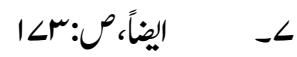

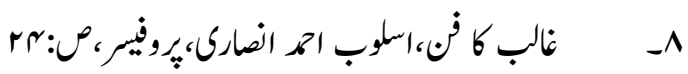

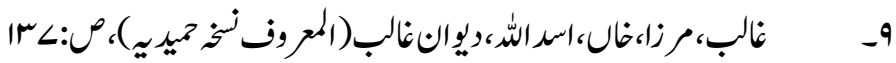

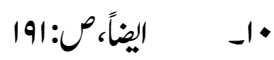

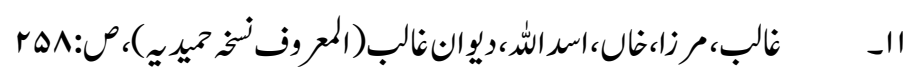

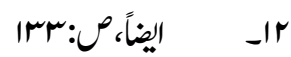

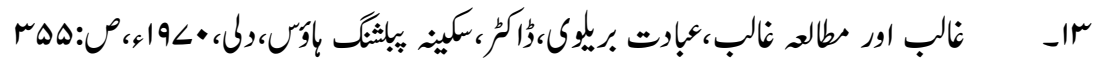

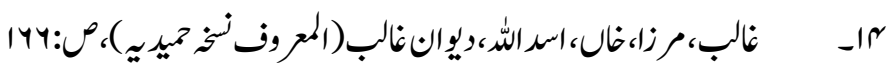

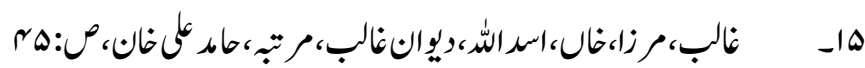

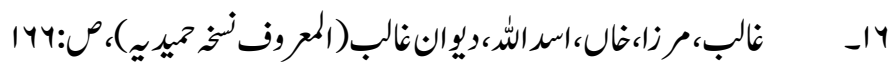
r

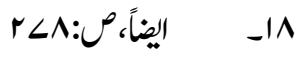

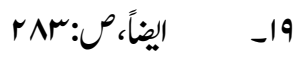

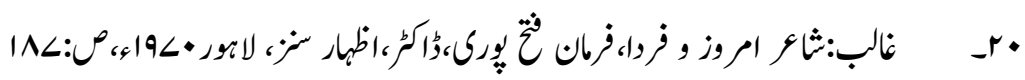

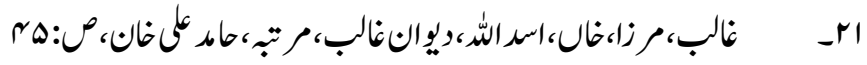




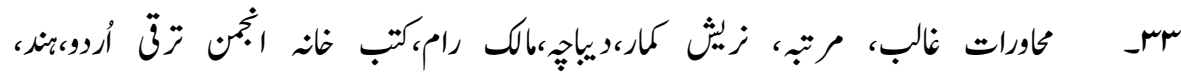

ر

rrس

$$
\text { هـ }
$$

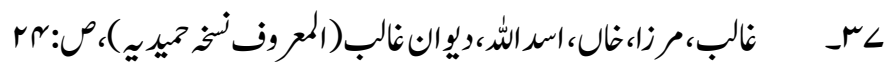

$$
\text { א }
$$

ه"

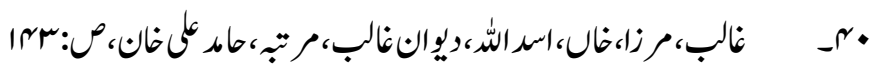

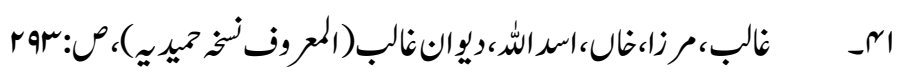

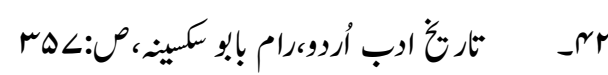

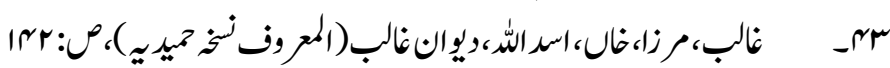

هrr

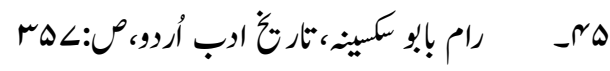




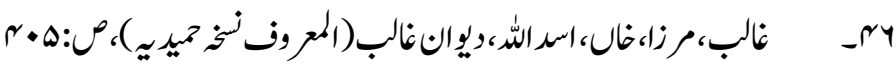

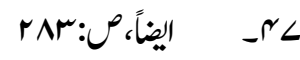

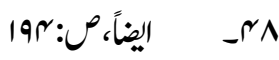

1919 إيناً

• هـ

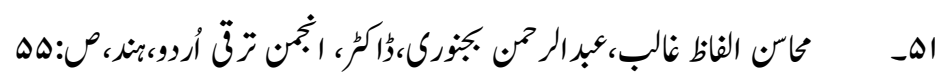

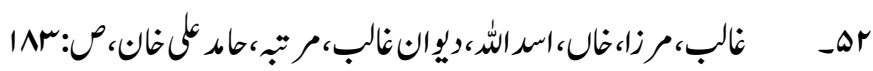

rهـ

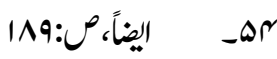

هـ

لهب

rALC: اليضاً

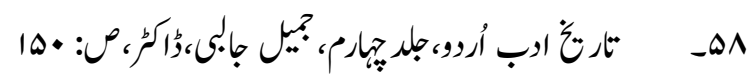

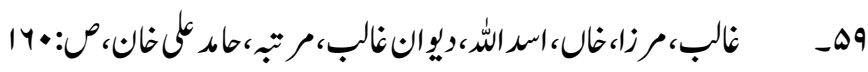

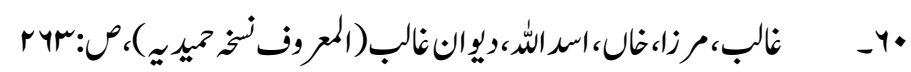

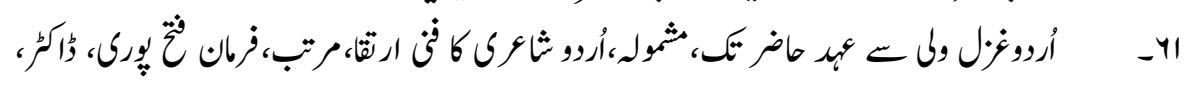

ira:e

rr

r

每

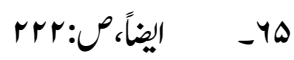

